\title{
Renal Biopsy in 2015 - From Epidemiology to Evidence-Based Indications
}

\author{
Marco Fiorentino ${ }^{a}$ Davide Bolignano $^{b, c}$ Vladimir Tesar ${ }^{d}$ Anna Pisano ${ }^{b}$ \\ Wim Van Biesen ${ }^{c}$ Graziella D'Arrigo ${ }^{b}$ Giovanni Tripepi $^{\text {b }}$ Loreto Gesualdo $^{a}$ \\ On behalf of the ERA-EDTA Immunonephrology Working Group
}

a Department of Emergency and Organ Transplantation, Nephrology, Dialysis and Transplantation Unit, University of Bari, Bari, and ${ }^{b}$ CNR-Institute of Clinical Physiology, Reggio Calabria, Italy; ${ }^{\complement}$ European Renal Best Practice, University Hospital Ghent, Ghent, Belgium; 'Department of Nephrology, 1st School of Medicine, Charles University, Prague, Czech Republic

\section{Key Words}

Renal biopsy · Epidemiology · Glomerulonephritides .

Indications · Nephrotic syndrome · Proteinuria $\cdot$ Hematuria . Acute kidney injury - Chronic kidney disease - Diabetes .

Elderly

\section{Abstract}

Background: Although the number of patients reaching end-stage kidney disease without a biopsy-proven diagnosis is increasing, the utility of renal biopsy is still an object of debate. We analyzed epidemiological data and the main indications for renal biopsy with a systematic, evidence-based review at current literature. Summary: There is a high discrepancy observed in biopsy rates and in the epidemiology of glomerular diseases worldwide, related to the different time frame of the analyzed reports, lack of data collection, the different reference source population and the heterogeneity of indications. The evidence-based analysis of indications showed that renal biopsy should be crucial in adults with nephrotic syndrome or urinary abnormalities as coexistent hematuria and proteinuria and in corticosteroid resistant-children with severe proteinuria. The knowledge of renal histology can change the clinical management in patients with acute kidney injury significantly, after the exclusion of pre-renal or obstructive causes of kidney damage. Scarce evidence indicates that renal biopsy can be useful in patients with advanced chronic kidney disease and its use should always be considered after weighing the benefits and potential risks. Renal biopsy should be crucial in patients with renal involvement due to systemic disease. In patients with diabetes with atypical features, renal biopsy may be fundamental to diagnose an unexpected parenchymal disease mislabeled as diabetic nephropathy. Finally, in elderly patients, the indications and the risks are not different from those in the general population. Key Message: Renal biopsy still remains a concrete approach for managing a substantial percentage of renal diseases.

(c) 2016 S. Karger AG, Basel

\section{Introduction}

The prevalence and incidence of chronic kidney disease (CKD) and end-stage kidney disease (ESKD) are steadily increasing. There are more than one million ESKD patients worldwide $[1,2]$. By 2030, the number of patients needing chronic replacement therapy is expected to increase by $60 \%$ [3]. Even though diabetes and hypertension are the most frequent causes of $\mathrm{CKD}$, recent evi-

\section{KARGER}

E-Mail karger@karger.com

www.karger.com/ajn (c) 2016 S. Karger AG, Basel

0250-8095/16/0431-0001\$39.50/0
Prof. Loreto Gesualdo

Division of Nephrology, Dialysis and Transplantation

'Aldo Moro' University of Bari

Piazza Giulio Cesare 11, IT-70124 Bari (Italy)

E-Mail loreto.gesualdo@uniba.it 
Fig. 1. Annual renal biopsy rate as reported in national and macro-regional registries (data are obtained from table 2).

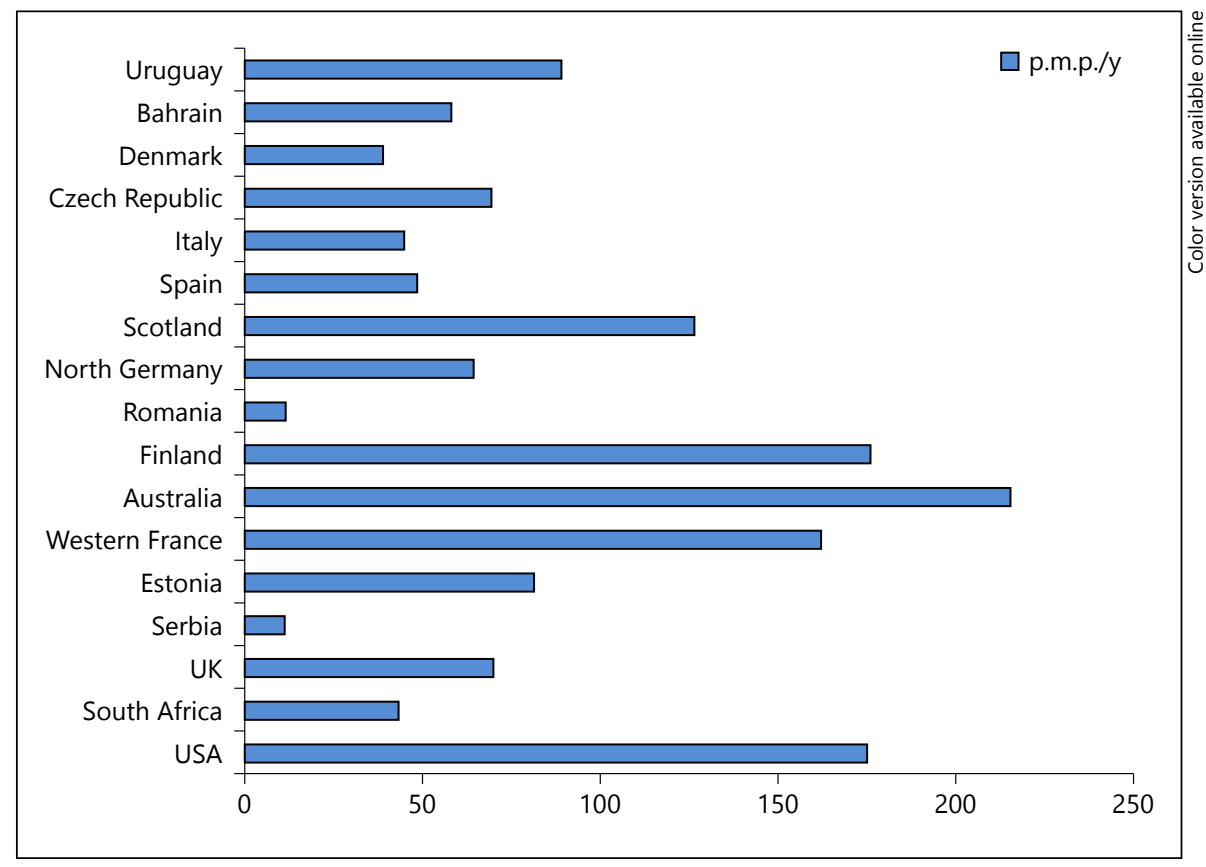

dence indicates that the number of patients starting chronic renal replacement therapy due to glomerular diseases is on the rise, currently ranging from 6.5 to 27 persons/million person/year (p.m.p./year) $[1,4]$.

In the past years, several noninvasive approaches for identifying early renal damage have been proposed, mostly based on 'omics' techniques (genomics, proteomics, metabolomics) for the evaluation of urine or plasma biomarkers [5]. However, the impact of these biomarkers on patient-management and long-term outcomes still awaits concrete validation in everyday clinical practice.

Although renal biopsy remains the gold standard for diagnosis [6], therapeutic management and outcome prediction in patients with renal parenchymal diseases, there is currently poor consensus about proper indications and clinical usefulness of this procedure [7]. As a result, the decision on performing renal biopsy is usually based on personal opinion and/or single-center policies.

A vast majority of studies agree that renal biopsy can improve clinical management of patients [8-12]. In a 3 -year prospective study of 80 patients with various renal parenchymal diseases, the predicted diagnosis, prognosis and therapeutic approach were modified in 44, 57 and $31 \%$ of the cases, respectively, based on histological findings [13]. In another observational study of 100 patients, renal biopsy led to therapeutic changes (particularly, introduction of immunosuppressive drugs) in $54 \%$ of cases [14]. Conversely, in a survey conducted on 24 board-cer- tified nephrologists, the knowledge of the renal histology did not significantly change the prognosis, therapy management or follow-up strategy [15].

Lack of clear guidelines on indications for renal biopsy may hamper the epidemiological classification of renal diseases, as well as the future of biomarkers validation. In the last report of the ERA-EDTA registry [4], the average percentage of prevalent and incident dialysis patients without a specific renal diagnosis stood at 15 and $16 \%$ respectively (ranging from $1.5 \%$ in Croatia to $38 \%$ in Romania), values very similar to those reported in UK [16] and US registries [1].

With this background in mind, we aim to review the role of renal biopsy in current practice (1) by analyzing epidemiology data on the clinical application of this technique at the global level and (2) by appraising the currently applied main indications for this procedure with a systematic, evidence-based approach to the available literature.

\section{Renal Biopsy: A Global Epidemiology Overview}

Based on registry and single-center data, there is a high variability in the rate of renal biopsies performed worldwide (fig. 1). In 9 national renal biopsy registries (Scotland, Italy, Spain, Czech Republic, Japan, Brazil, Bahrain, Uruguay, Denmark) [17-28], the median total 
Table 1. Factors influencing the variability of biopsy practice worldwide
Different time frame of reports
Lack of renal biopsy data collection
Reference source population
Social and economic status
Heterogeneity of indications of renal biopsy

number of biopsies performed was 1,818 , ranging from 498 [20] to 14,607 [24]. In data from 6 macro-regional databases (France, Finland, Romania, Australia, North Germany, West Saudi Arabia) [29-35] and 12 single-center reports [36-47], the overall number of biopsies ranged from 251 [29] to 3,310 [34].

Higher biopsy rates were reported in the Australian database (215 p.m.p./year) [32] and in single-center experiences of the University Hospital of Helsinki, Finland (176 p.m.p./year) [34] and the Olmsted County, USA (up to 175 p.m.p./year) [42]. Conversely, very low rates were reported in 2 regional databases in Romania (11.3 p.m.p./ year) [33] and in a Serbian single-center biopsy registry (10.8 p.m.p./year) [38]. The high variability can be explained by different factors (table 1). First, the time frame considered by each report was different. For instance, the Olmsted county renal biopsy study [42] encompassed a 30-year-observation (1974-2003), while the Victoria registry (Australia) [32] was limited to 3 years (1995-1997). Furthermore, only 9 reports $[17,19,20,35-38,40,48]$ covered up to the first decade of the 21st century, while the remainder were mostly focused on the nineties. Lack of temporal overlap among these different registries limits the possibility to compare data; moreover, different trends in the diagnosis of different glomerular diseases might exist according to the time period and the time frame considered [42]. Moreover, the actual registry may miss renal biopsy registration due to the voluntary data collection. Therefore, cumulative data provided by most registries may not properly reflect the current situation in a given country. Moreover, a majority of cases analyzed were strictly dependent on the reference source population, which may affect the generalizability of the reported annual rate. Finally, since there are different opinions on the indications for renal biopsy, this may have had a significant impact on the single-specialist decision about the choice of performing this procedure. Moreover, the social and economic status and the financial resources allocated to nephrology services are profoundly different among countries. For instance, in 2 registries [34, 38], the lower

Epidemiology and Indications for Renal Biopsy biopsy rate was motivated by the economic recession in certain historical periods.

The mean age of subjects undergoing renal biopsy was also very homogeneous, being on average $40.6 \pm 5.5$ (range 33-56). With respect to gender, a majority of patients analyzed were male (percentage ranging from 50.5 to $60 \%$ ), but reports from South Africa, Brazil and HongKong were an exception $[18,37,47]$. The most frequent indication for performing renal biopsy was the presence of nephrotic syndrome (NS, mean $40.35 \%$, range 20 $70 \%)$.

Table 2 summarizes main data on the epidemiology of renal biopsy worldwide.

The incidence rate of patients who have been diagnosed with any glomerulonephritis (GN) within Europe has increased over the last 4 decades, peaking at $15.3 \%$ of the overall renal diagnoses made in 2010-2012 [4]. However, in about $21 \%$ of cases, the presence of GNs was only based on clinical signs and not histologically classified. The epidemiology of GNs is strongly influenced by the biopsy rate. In fact, renal registries with lower biopsy rates can be more likely to have a low incidence of biopsy-proven glomerular disease and vice-versa. Geography, race, age and indications for renal biopsy are other well-recognized factors that may impact the epidemiology of primary GN. Furthermore, poor socio-economic conditions may affect the epidemiology of GNs in at least 2 possible ways. First, according to the 'hygiene hypothesis' [49], the increased exposure to bacterial antigens in developing countries may reflect a different pattern of response of the immune system, which translates in a different exacerbation of particular glomerular diseases (higher prevalence of membrano-proliferative GN (MPGN), in developing areas, higher prevalence of IgA-nephropathy (IgAN), and minimal change disease (MCD), in more developed countries). Accordingly, in the Romanian database [33], the improvement of the national health system, as well as the economic status and resources allocated to preventive medicine, were followed by a reduction of MPGN and infection-related GNs. In addition, although light microscopy and immunofluorescence techniques were almost widely performed, poor economic resources may also limit the overall accessibility to appropriate techniques for making clear-cut diagnoses, such as electronic microscopy (table 2).

As shown in table 3 and figures 2-4, IgAN represents the most frequent primary, biopsy-proven GN in 6 out of 8 national registries (Italy, Spain, Czech Republic, Denmark, Scotland, Japan) [17, 19, 22-28], in 3 macroregional (Western France, Finland, Victoria-Australia) 


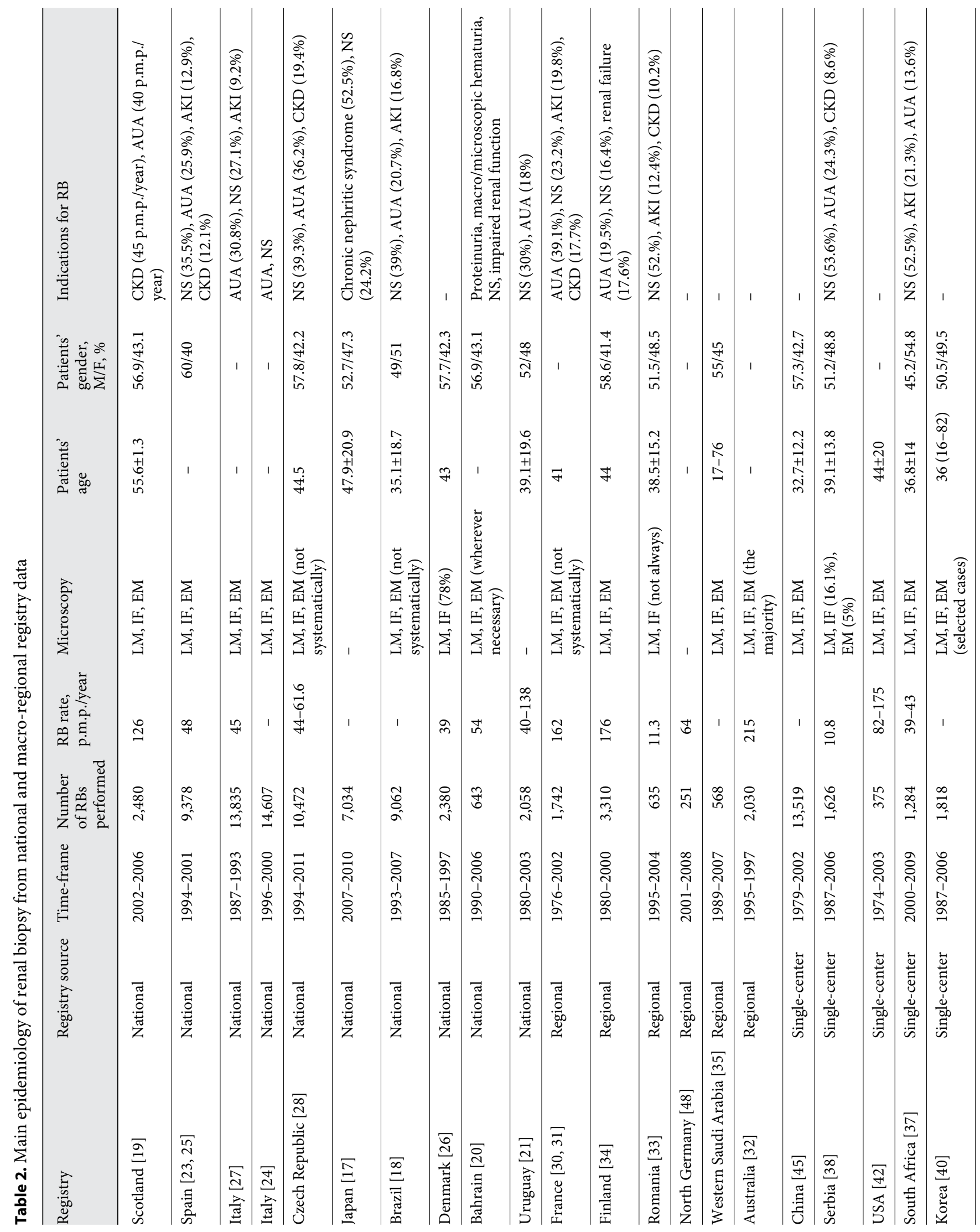




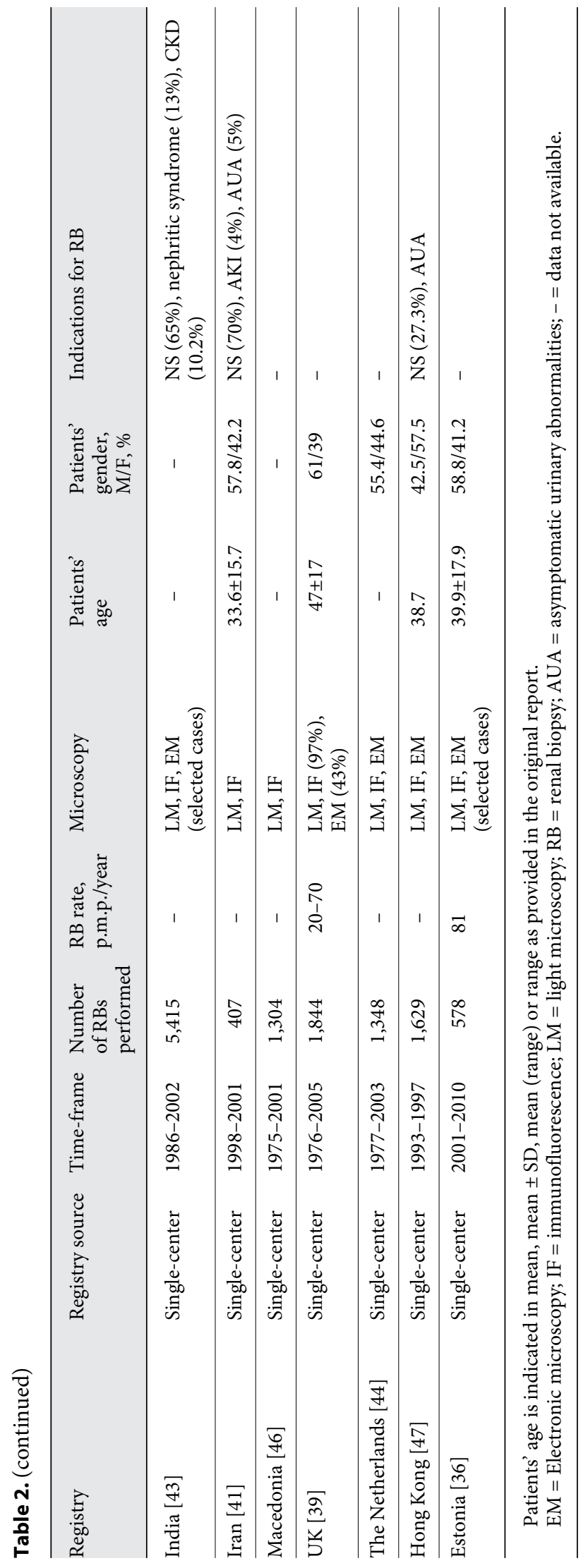

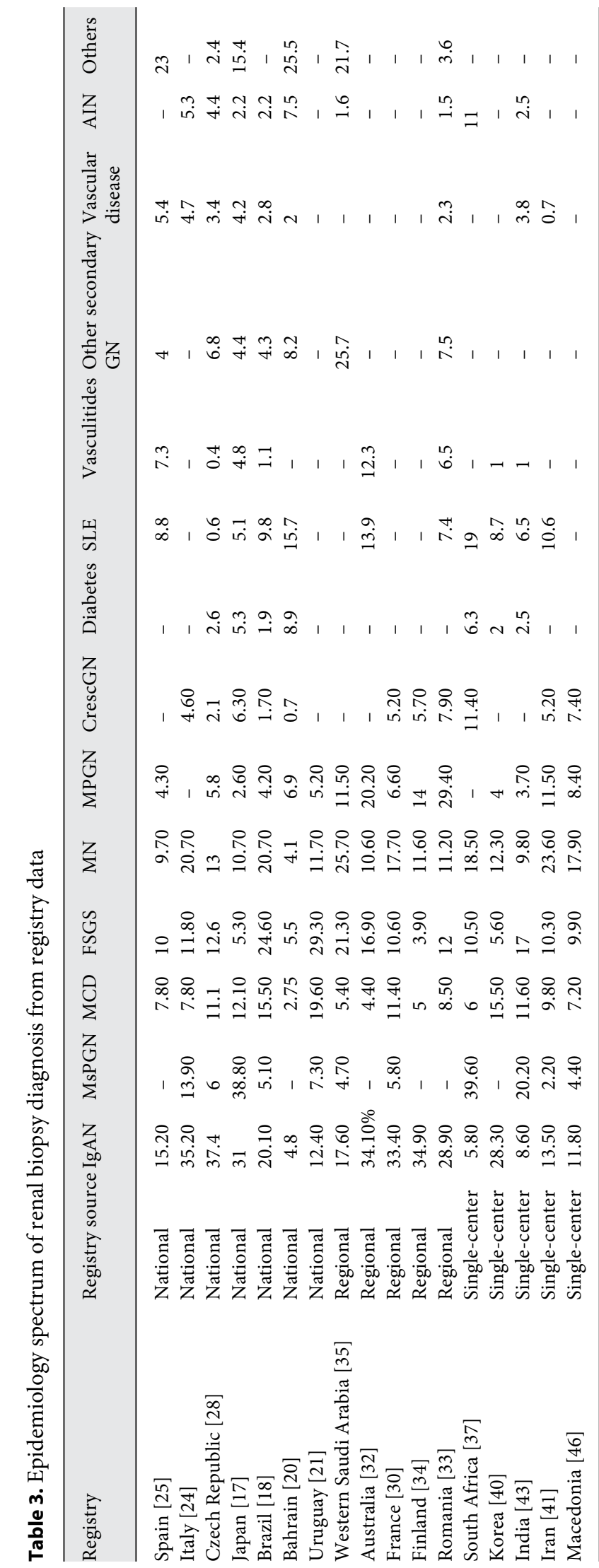

Am J Nephrol 2016;43:1-19

DOI: $10.1159 / 000444026$ 


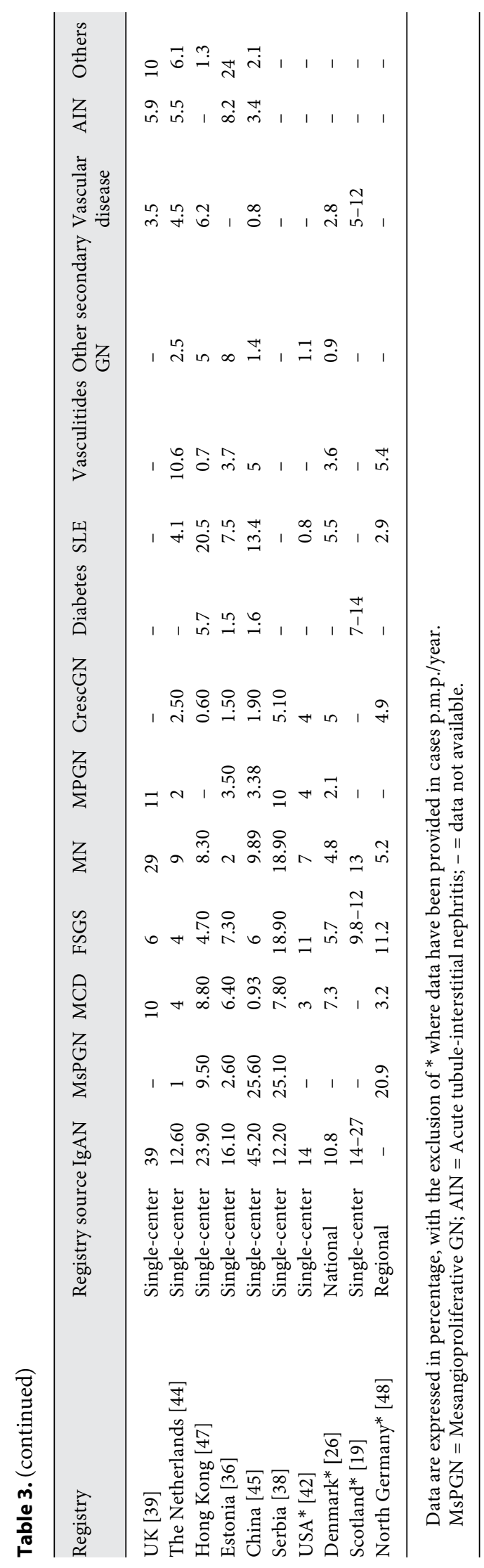

$[30,32,34]$ and 7 single-center databases $[36,39,40,42$, $44,45,47]$ with a percentage of total diagnoses ranging from $12.6 \%$ [44] to $45 \%$ [45]. Focal segmental glomerulosclerosis (FSGS) was the most frequent primary GN in Brazil (24.6\%) [18], in the Uruguayan registry of glomerulopathies [21] (29.3\%) and in Bahrain (23.8\%) [20,35]. Conversely, MPGN appeared to be the most frequent glomerular disease diagnosed in Romania (29.4\%) [33]. Membranous nephropathy ( $\mathrm{MN}$ ) predominated in 2 single-center retrospective reports in Macedonia (17.9\%) [46] and Iran (23.6\%) [41]. Non-IgA mesangioproliferative GN was the most frequent primary GN in Serbia (25.1\%) [38]. The most frequent secondary GN was lupus nephritis in Spain (8.8\%) [25], Italy (2.6 p.m.p./year) [24, 27], Brazil (9.8\%) [18], Bahrain (15.7\%) [20], Australia (13.9\%) [32], Romania (7.4\%) [33], Korea (8.7\%) [40], China [45] and Hong Kong (20.5\%) [47]; diabetic nephropathy (DN) predominated in Czech Republic (2.6\%) [22], Japan (5.3\%) [17] and Scotland (7-14 p.m.p./year) [19]. Acute tubulo-interstitial nephritis (AIN) diagnosis was reported in 13 registries, with a percentage ranging across $1.5 \%$ [33] to $11 \%$ [37] of overall diagnosis.

\section{Renal Biopsy: Indications}

Table 2 and figure 5 highlight the high variability in the main indications for renal biopsy among national and macro-regional registries. Indeed, there are a few indications for which the need for renal biopsy is almost universally recognized (e.g. NS in adults). Conversely, in a majority of conditions including urinary abnormalities, diabetes, acute kidney injury (AKI) or CKD of unknown origin, the usefulness and timing of this procedure still remain a subject of debate. We adopted a systematic approach to identify any evidence available supporting or contradicting the main known clinical indications for renal biopsy. PubMed and Ovid MEDLINE were searched for articles without time and language restriction through a focused search strategy (table 4). References from relevant studies and reviews published on the same topic were screened for supplementary articles. The search was designed and performed by 3 authors (D.B., M.F. and A.P.).

\section{Nephrotic Syndrome}

NS is the most frequent indication for renal biopsy in adults $[50,51]$, as shown by 3 national registries $[18,21$, 25], one macro-regional database [33] and 3 single-center reports $[37,41,43]$. 
Fig. 2. Different incidence of primary glomerulonephritides as reported in national registries (data are obtained from table 2). MsPGN = Mesangioproliferative GN.
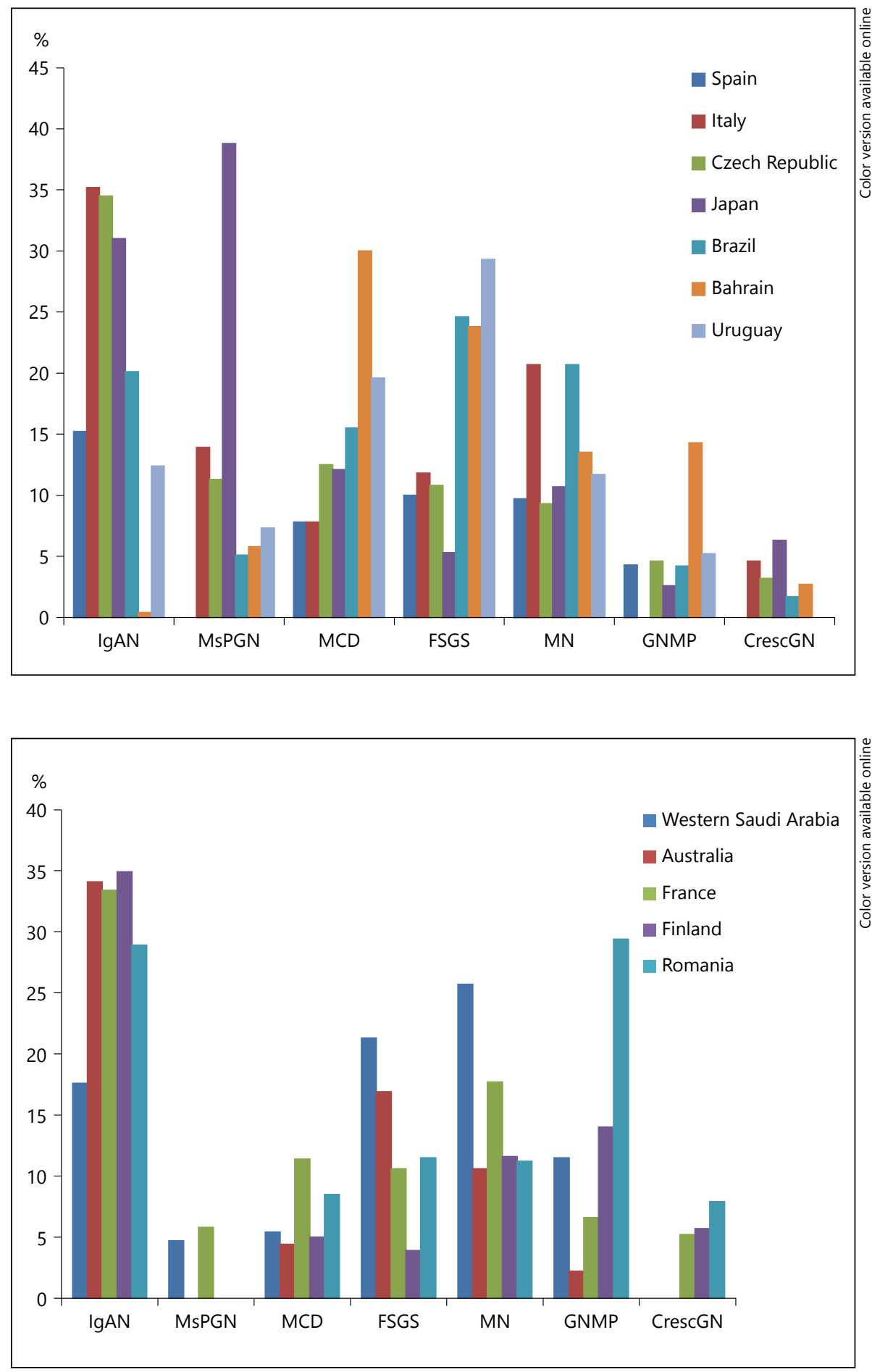

Fig. 3. Different incidence of primary glomerulonephritides as reported in macroregional registries (data are obtained from table 2). MsPGN = Mesangioproliferative GN.
The most frequent histological patterns related to primary NS in adults are MN, FSGS and MCD [52, 53]. However, cases of NS were also found to be due to diabetes, systemic lupus erythematosus (SLE), infections, multiple myeloma, amyloidosis or neoplasias [54].

Epidemiology and Indications for Renal Biopsy
Renal biopsy is fundamental to assess not only the type but also the degree of disease activity. The overall prognosis and response to treatment often depend on the severity of histological lesions and their reversibility [8]. For instance, the presence of glomerulosclerosis, arterioscle- 


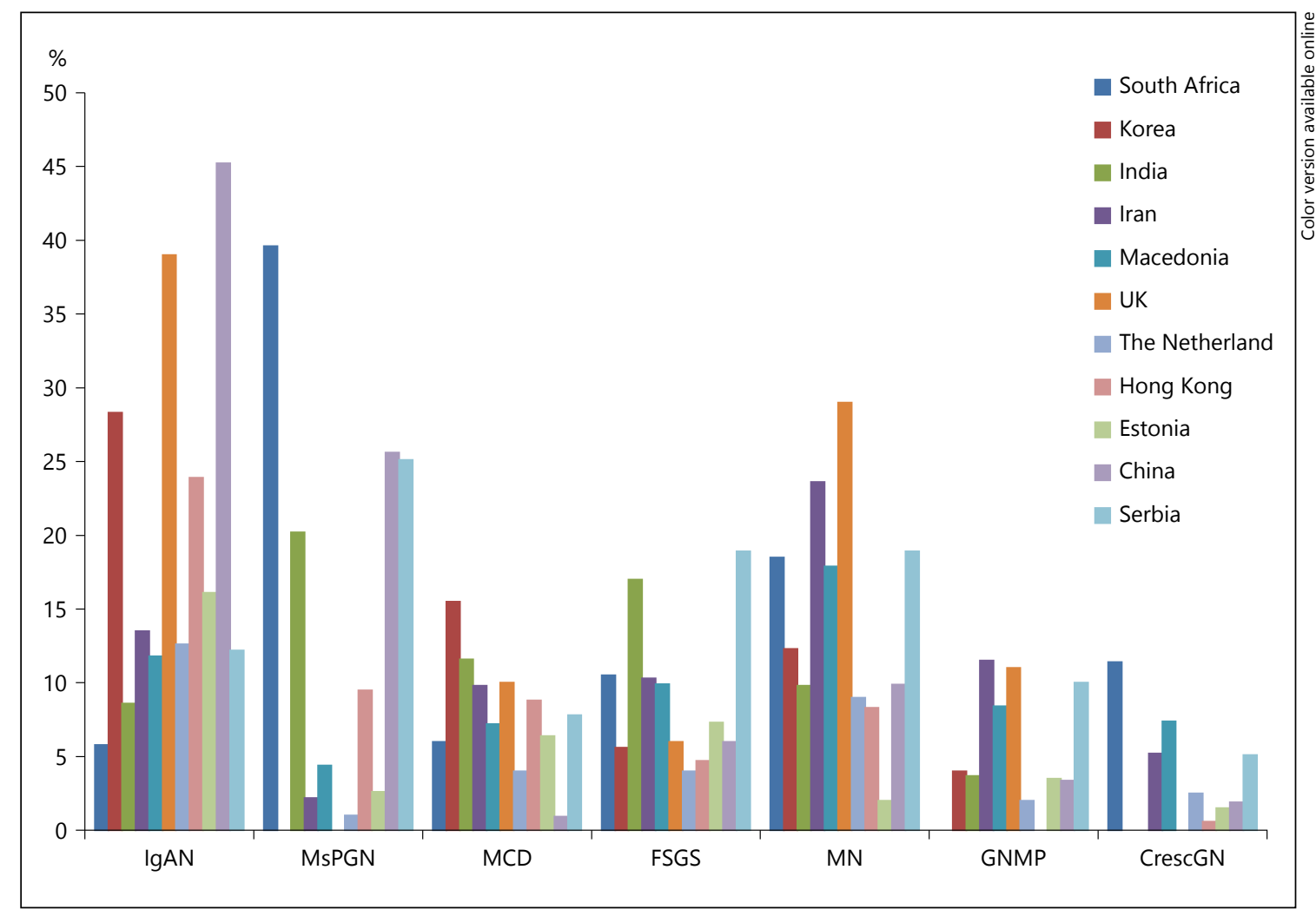

Fig. 4. Different incidence of primary glomerulonephritides in single-center reports (the data are obtained from table 2). MsPGN = Mesangioproliferative GN.

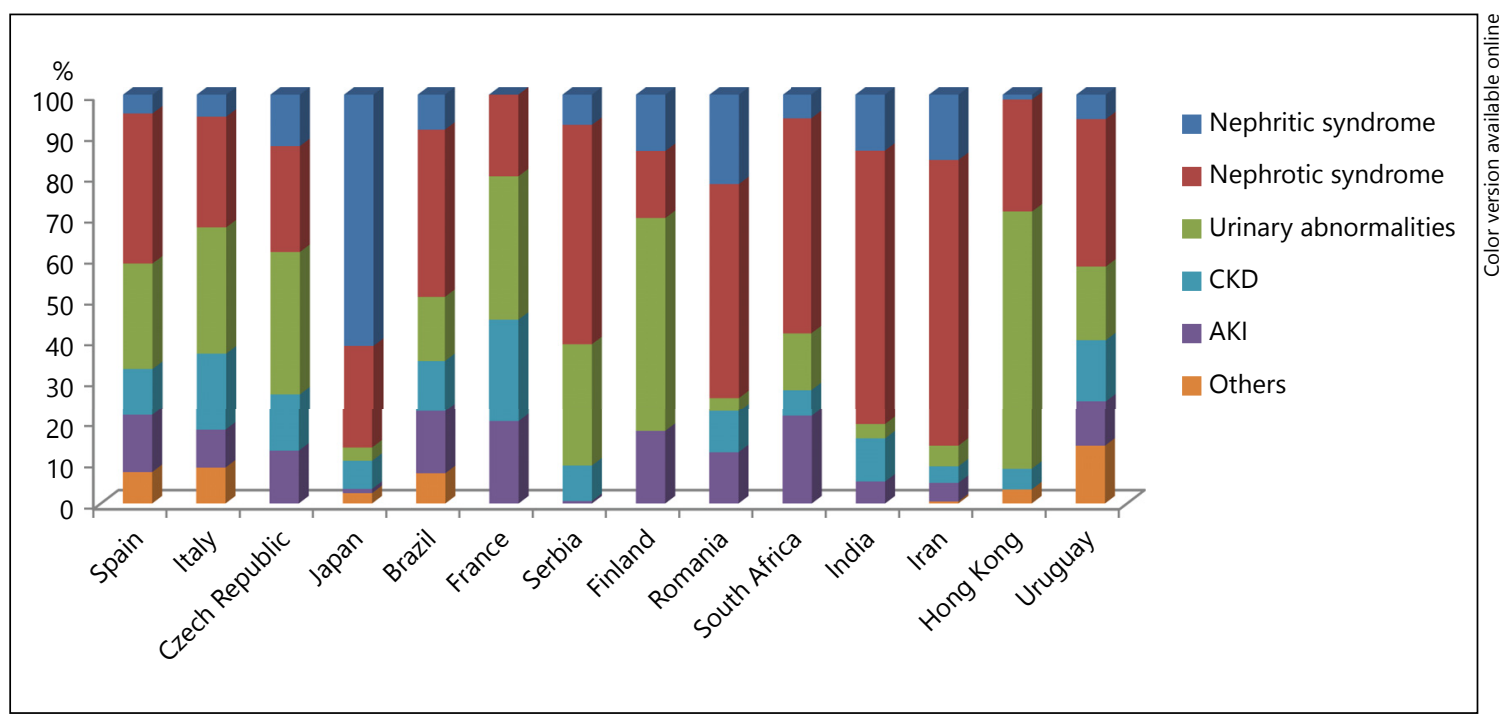

Fig. 5. Main indications for renal biopsy as reported in national and macro-regional registries. Data are obtained from the national and macro-regional registries reported in the text. 
rosis, and interstitial fibrosis are all suggestive of an irreversible process that is less likely to respond to treatment; conversely, the presence of active lesions potentially indicates good responsiveness to corticosteroid treatment. Therapeutic effectiveness is also strongly influenced by the histological diagnosis per se. MCD is usually controlled by corticosteroid treatment alone, while $\mathrm{MN}$ and FSGS often require the addition of other immunosuppressive agents [55]. SLE patients with more aggressive and acute lesions (class IV nephritis) may benefit from treatment with corticosteroids and other cytotoxic drugs, whereas those with less severe or chronic lesions may have less to gain. Renal biopsy in these patients is thus mandatory not only for diagnosis but also for the early identification of renal flares [56, 57]. NS in multiple myeloma may reflect the presence of amyloidosis or lightchain deposition. Since the presence of active renal lesions predicts poor prognosis, renal biopsy may be helpful to plan early countermeasures [58].

Histological diagnosis is therefore helpful in driving therapeutic management of patients with NS $[9,55,59]$. Indeed, in an old prospective study [9], renal biopsy was useful to change clinical approaches in 24 of 28 patients presenting with NS. In another study [60] of 276 native renal biopsies performed on 266 patients, histological information produced significant changes in clinical management in $42 \%$ of cases, particularly in patients with nephrotic range proteinuria (86\%). Finally, in another prospective analysis of 108 biopsy specimens, clinical and pathological diagnoses differed in $63 \%$ and therapeutic approach was altered in $34 \%$ of cases, particularly in subjects with NS of rapid onset [61]. Moreover, the knowledge of renal histology may be crucial, particularly when patients are transplant candidates, considering the risk of recurrent disease after kidney transplantation.

The indications for renal biopsy in NS are more restrictive in pediatric subjects. It is widely accepted that NS in children does not require any histological evaluation as first-line approach $[55,62]$. Indeed, in this population about $90 \%$ of idiopathic NS are related to minimal glomerular lesions with very high response-rate to corticosteroid treatment and a very low risk of progression to ESKD $[63,64]$. In a study of 30 children, the response to cyclophosphamide therapy correlated better with the initial corticosteroid response than to renal histopathology [65]. Similar findings were reported in a retrospective analysis of 85 patients with steroid-sensitive NS [66]. Conversely, renal biopsy in children should be considered if NS is not responsive to standard corticosteroid treatment or is associated to frank renal impairment $[55,67]$.

Epidemiology and Indications for Renal Biopsy
Table 4. Literature search criteria adopted

Ovid-MEDLINE

1 ((Kidney or renal) and biopsy adj1 indicat*).mp,kw,tw.

Hematuria.mp,kw,tw.

(Microhematuriaormicro-hematuria).mp,kw,tw.

(Macrohematuria or macro-hematuria).mp,kw,tw.

Nephroticsyndrome.mp,tw,kw.

Nephrosis.mp,tw,kw.

Proteinur*.mp,tw,kw.

(Macroproteinur* or macro-proteinur*).mp,kw,tw.

Nephritic syndrome.mp,kw,tw.

2 or 3 or 4 or 5 or 6 or 7 or 8 or 9

Renal insufficiency (including related terms)

Kidney failure (including related terms)

Kidney diseases (including related terms)

(Chronic kidney or chronic renal).tw.

(CKF or CKD or CRF or CRD).tw.

(Acute kidney or acute renal).tw.

(AKI or ARF).tw.

11 or 12 or 13 or 14 or 15 or 16 or 17

Diabetes mellitus (including related terms)

Exp diabetes mellitus, type $1 /$

Exp diabetes mellitus, type 2/

Diabetic nephropathies (including related terms)

Diabet*.tw.

(NIDDM or IDDM).tw.

Exp hyperglycemia/

19 or 20 or 21 or 22 or 23 or 24 or 25

10 or 18 or 26

1 and 27

Limit 28 to human

\section{PubMed}

((Chronic kidney disease) OR (renal impairment) OR (impaired kidney function) OR (acute renal failure) OR (acute kidney injury) OR (diabetes) OR (diabetic nephropathy) OR

(proteinuria) OR (hematuria) OR (nephrotic syndrome) OR (nephrotic syndrome) OR (nephrosis) OR (diagnosis)) AND (kidney biopsy indications)

\section{Urinary Abnormalities}

Urinary abnormalities (such as microhematuria or non-nephrotic proteinuria) emerged as the most common reasons for performing renal biopsy in 2 national registries [22, 24, 28], in 2 macro-regional reports [31, 34] and in a single-center database [47].

There is no consensus on the use of renal biopsy in patients with isolated non-nephrotic proteinuria. Hama et al. [68] suggested that urinary protein/creatinine ratio $\geq 0.5 \mathrm{~g} / \mathrm{g}$ may represent an optimal cut-off to distinguish between minor glomerular lesions and significant glomerular disease in children with asymptomatic proteinuria. In a survey made among Italian nephrologists [69], isolated proteinuria $<1 \mathrm{~g} /$ day was not considered as a suf- 
Table 5. Main characteristics of the reviewed studies on diabetic patients undergoing renal biopsy

\begin{tabular}{|c|c|c|c|c|c|c|}
\hline Study/year & Country & $\mathrm{n}$ & \multicolumn{3}{|c|}{ Histological finding } & NDRD diagnosis \\
\hline Richards et al. [139], 1992 & United Kingdom & 68 & 62 & 34 & 4 & MN (7\%), IgAN (2\%), PICGN (2\%), MPGN (2\%) \\
\hline Parving et al. [135], 1992 & Denmark & 35 & 77.1 & 20 & 2.9 & Mesangio-proliferative GN \\
\hline Gambara et al. [114], 1993 & Italy & 52 & 36.5 & 33 & 30.5 & IgAN, MN, FSGS, MCD, PICGN (4\%) \\
\hline John et al. [123], 1994 & India & 80 & 18.7 & 60 & 21.3 & $\begin{array}{l}\text { MCD (16\%), IgAN (8\%), MN (8\%), AIN (6\%), } \\
\text { FSGS (6\%) }\end{array}$ \\
\hline $\begin{array}{l}\text { Olsen and Mogensen [134], } \\
1996\end{array}$ & Denmark & 33 & 88 & 3 & 9 & $\begin{array}{l}\text { IgAN (3\%), mesangio-proliferative GN (3\%), } \\
\text { CrioGN (3\%) }\end{array}$ \\
\hline Schwartz et al. [140], 1998 & United States & 36 & 94 & 6 & - & $\operatorname{IgAN}(3 \%), \mathrm{MN}(3 \%)$ \\
\hline Lee et al. [126], 1999 & South Korea & 22 & 36.4 & 50 & 13.6 & $\operatorname{IgAN}(22 \%), \operatorname{MN}(21 \%), \operatorname{MCD}(21 \%), \operatorname{AIN}(5 \%)$ \\
\hline Cordonnier et al. [113], 1999 & United Kingdom & 26 & 85 & 15 & - & - \\
\hline Nzerue et al. [132], 2000 & United States & 31 & 41.9 & 19.4 & 38.7 & $\begin{array}{l}\text { FSGS (18\%), nephrosclerosis (17\%), MN (6\%), } \\
\text { PICGN }(6 \%)\end{array}$ \\
\hline Christensen et al. [112], 2000 & Denmark & 51 & 69 & 13 & - & IgAN (8\%), MPGN (4\%) \\
\hline Izzedine et al. [122], 2001 & France & 21 & 62 & 38 & - & FSGS, IgAN, vascularnephropathy \\
\hline Suzuki et al. [144], 2001 & Japan & 109 & 73.3 & - & 26.7 & $\begin{array}{l}\text { IgAN (44.8\%), proliferative GN (37.9\%), MN } \\
(6.9 \%) \text {, AIN (6.9\%), FSGS (3.4\%) }\end{array}$ \\
\hline Wong et al. [146], 2002 & China & 68 & 35 & 46 & 19 & $\begin{array}{l}\text { IgAN (19\%), nephrosclerosis (13\%), MN (12\%), } \\
\operatorname{MCD}(6 \%)\end{array}$ \\
\hline Premalatha et al. [138], 2002 & India & 18 & 50 & 50 & - & MN (33.3\%), AIN (12.5\%), MCD (12.5\%) \\
\hline Rychlik et al. [22], 2004 & Czech Republic & 163 & 42.4 & 47.5 & 10.1 & IgAN (15\%), MN (12\%), PICGN (12\%) \\
\hline Tone et al. [145], 2005 & Japan & 97 & 36 & 47.5 & 16.5 & $\operatorname{IgAN}(16 \%)$, MN (13\%), MCD (8\%), FSGS (5\%) \\
\hline Moger et al. [130], 2005 & India & 26 & 34.6 & 23.1 & 42.3 & $\begin{array}{l}\text { Proliferative GN (27\%), AIN (15.3\%), PICGN } \\
(11.5 \%)\end{array}$ \\
\hline Soni et al. [143], 2006 & India & 160 & 27.5 & 42.5 & 30 & $\begin{array}{l}\text { AIN }(18.1 \%), \text { post-infectious GN }(17.2 \%), \mathrm{MN} \\
(11.2 \%), \text { FSGS }(7.7 \%)\end{array}$ \\
\hline Pham et al. [136], 2007 & United States & 232 & 27.5 & 53.2 & 19.3 & $\begin{array}{l}\text { FSGS (21\%), MCD (15.3\%), IgAN (15.3\%), MN } \\
(13.3 \%)\end{array}$ \\
\hline Huang et al. [120], 2007 & China & 52 & 55.7 & 38.5 & 5.8 & Mesangial proliferative GN (9.6\%), MCD (7.7\%) \\
\hline Kharrat et al. [124], 2007 & Tunisia & 72 & 34.1 & 69.5 & - & - \\
\hline Prakash et al. [137], 2007 & India & 23 & 56.5 & 30.5 & 13 & MN (8.7\%), FSGS (8.7\%) \\
\hline
\end{tabular}


Table 5. (continued)

\begin{tabular}{|c|c|c|c|c|c|c|}
\hline Study/year & Country & $\mathrm{n}$ & $\mathrm{DN}, \%$ & NDRD, \% & mixed, \% & NDRD diagnosis \\
\hline Akimoto et al. [105], 2008 & Japan & 50 & 68 & 26 & 6 & MN (8\%), IgAN (6\%), MPGN (6\%) \\
\hline Lin et al. [127], 2009 & Taiwan & 50 & 48 & 22 & 30 & $\operatorname{AIN}(46 \%), \mathrm{MN}(19.2 \%), \operatorname{IgAN}(11.5 \%)$ \\
\hline Arif et al. [106], 2009 & Pakistan & 73 & 27.3 & 31.7 & 41 & FSGS/MCD (30.56\%), MN (8.3\%), IgAN (5.5\%) \\
\hline $\begin{array}{l}\text { Hashim Al-Saedi [118], } \\
2009\end{array}$ & Iraq & 80 & - & 100 & - & $\begin{array}{l}\text { MPGN (40\%), FSGS (25\%), MN (20\%), MCD } \\
\text { (10\%), amyloidosis ( } 5 \%)\end{array}$ \\
\hline Mou et al. [131], 2010 & China & 69 & 47.8 & 52.2 & - & $\begin{array}{l}\text { FSGS (37.7\%), IgAN (15.9\%), MCD (15.9\%), MN } \\
(8.7 \%)\end{array}$ \\
\hline Chang et al. [110], 2011 & South Korea & 119 & 36.2 & 53.8 & 10 & $\begin{array}{l}\mathrm{MN}(32.9 \%), \mathrm{MCD}(15.8 \%), \text { FSGS }(11.8 \%), \text { IgAN } \\
(11.8 \%)\end{array}$ \\
\hline Bi et al. [107], 2011 & China & 220 & 54.5 & - & 45.5 & $\begin{array}{l}\text { IgAN (34\%), MN (22\%), mesangial proliferative } \\
\text { GN (14\%) }\end{array}$ \\
\hline Zhang et al. [149], 2011 & China & 130 & 73.9 & 26.1 & - & $\operatorname{IgAN}(16.9 \%), \mathrm{MN}(6.15 \%)$ \\
\hline Y et al. [148], 2012 & Marocco & 16 & 62.5 & 37.5 & - & IgAN (19\%), myeloma (6\%) \\
\hline Yaqub et al. [147], 2012 & Pakistan & 68 & 31 & 52 & 17 & $\begin{array}{l}\text { AIN }(26.4 \%) \text {, post-infectious GN }(10.3 \%), \text { MN } \\
(5.9 \%) \text {, PICGN }(5.9 \%)\end{array}$ \\
\hline Oh et al. [133], 2012 & South Korea & 126 & 39.7 & 51.6 & 8.7 & $\begin{array}{l}\text { IgAN (16\%), MN (11.9\%), FSGS (7.6\%), MPGN } \\
(4.7 \%)\end{array}$ \\
\hline Sharma et al. [102], 2013 & United States & 620 & 37 & 36 & 27 & $\begin{array}{l}\text { ATN (17-43\%), FSGS (13-22\%), hypertensive } \\
\text { nephrosclerosis (19\%), IgAN (7-11\%) }\end{array}$ \\
\hline Harada et al. [117], 2013 & Japan & 55 & 54.5 & 34.5 & 10.9 & IgAN (23.6\%), FSGS (5.4\%), MN (1.8\%) \\
\hline
\end{tabular}

ATN = Acute tubular necrosis; Crio-GN = crioglobulinemic GN; PICGN = pauci-immune crescentic GN; - = data not available.

ficient indication for renal biopsy in the absence of other serum and urinary abnormalities. Conversely, patients with proteinuria $\geq 1 \mathrm{~g} /$ day would deserve renal biopsy for clarifying the nature of the underlying nephropathy [69] and should periodically be followed if such levels persist over time [70].

The diagnostic approach to isolated microscopic hematuria (IMH) changes according to the patient's age
[71]. In children, IMH is usually associated with hypercalciuria (30-35\%), hyperuricemia (5-20\%) and glomerular disease, such as IgAN and thin basement membrane nephropathy [72]. Zhai et al. [73] described the histological patterns of 112 renal biopsies in children with asymptomatic urinary abnormalities. Mild glomerular lesions predominated in patients with $\mathrm{IMH}$ while chronic GNs (particularly, IgAN) were more 
prevalent in patients where proteinuria and hematuria co-existed. The utility of renal biopsy in these patients is highly debated since the overall prognosis in the midlong term is excellent. In a study of 251 children with IMH [74], no patients developed hypertension or any other sign of renal impairment over a 7-year follow-up. Similar observations were reported by Lee et al. [75] in a study on 289 children undergoing renal biopsy for the same indication.

Conversely, the use of renal biopsy might be very important to predict the disease course if IMH is associated with proteinuria or impaired renal function or in the presence of a history of macroscopic hematuria [71, 76, 77]. In a retrospective study of 169 young patients undergoing renal biopsy for microscopic hematuria [78], the severity of the glomerular findings and the progression of renal disease were strictly correlated to urinary protein excretion.

In a study of 351 children with various urinary abnormalities, normal histology was more frequent in subjects with IMH than in those with both microhematuria and proteinuria. Moreover, in these latter, the worsening of proteinuria or the impairment in renal function occurred more significantly over a 10-year follow-up [79].

In adults presenting with IMH, non-glomerular causes (such as nut-cracker syndrome, infectious diseases, lithiasis or neoplastic disease) should firstly be excluded $[71,80]$; the contribution of finding dysmorphic erythrocytes and acanthocytes should be important for the diagnostic decision [81]. Glomerular causes of IMH are miscellaneous and mostly represented by IgAN, Alport syndrome, thin basement membrane nephropathy and FSGS [82].

Renal biopsy in IMH may be more useful to assess the individual risk of progressive renal disease or inspire the screening of relatives (e.g. in case of Alport syndrome), than to guide clinical management [83]. Conversely, the presence of pathological albuminuria or other altered serum parameters might be a stronger indication for renal biopsy $[69,84]$, as this may reflect a more prominent histopathological damage [85] and higher risk of renal disease progression $[86,87]$.

\section{Acute Kidney Injury}

Although AKI patients are notoriously at high risk for post-biopsy bleeding $[88,89]$, in subjects with no evidence of pre-renal or obstructive diseases, the benefits of renal biopsy may outweigh the risks as the histological diagnosis might be useful to guide therapy and to predict outcomes.
Many, non-evidence-based biopsy policies have been proposed so far for approaching AKI patients such as an unknown origin of AKI, AKI duration of more than 3 or 4 weeks [69] or the presence of extra-renal manifestations, suggestive of a systemic disease.

In an old report of 84 patients presenting with AKI and evidence of intrinsic renal disease, renal biopsy was useful in establishing the diagnosis, in indicating the reversibility of the lesion and in guiding treatment [90]. In another study conducted in the nineties, renal biopsy altered the management of $71 \%$ of patients with AKI [9].

In another milestone paper of $250 \mathrm{AKI}$ patients, one half of which had parenchymal diseases, the etiology of AKI could be determined only by renal biopsy and this procedure was also useful to drive diagnosis and treatment [91]. In a series of 259 patients with AKI undergoing renal biopsy [92], glomerular disease (particularly pauci-immune crescentic GN (crescGN) and post-infectious GN, anti-GBM nephritis, IgAN) was the most frequent histological pattern, while tubulo-interstitial disease (AIN and acute tubular necrosis) and vascular injury (atheroembolic disease) accounted for about 40 and $12 \%$ respectively of the remaining diagnoses. The clinical diagnosis corresponded with histological findings in two third of cases and patients with tubulo-interstitial disease had a better renal prognosis as compared with those with GNs and renal vasculitis [92]. AIN and rapidly progressive GN were the most frequent histological findings in another study of 109 patients with unexplained acute renal impairment and normal-size kidney [93]. Of note, $52 \%$ of patients with AIN and $60 \%$ with rapidly progressive glomerular damage improved or remained stable after the establishment of appropriate treatment.

\section{Chronic Kidney Disease}

The utility of renal biopsy in patients with CKD is even more controversial. These subjects may have a higher risk of bleeding and have lower chances of diagnostic success, particularly when the kidneys are smaller and more scarred [94]. Nevertheless, renal biopsy in CKD patients is relatively a safe procedure as reported in several studies [94-99] and may represent a valid tool for clinical management. Renal tissue obtained by biopsy cannot give a great quantity of information if chronic damage (tubulointerstitial fibrosis, glomerulosclerosis, arteriosclerosis) prevails [8] and there is usually an inverse relationship between the degree of renal function and the need for therapeutic changes [94]. Sparse evidence indicates that
Fiorentino et al. 
the histological diagnosis made in CKD patients can differ from the expected, clinically made diagnosis in a significant percentage of cases [95-97]. In patients with NS and non-advanced CKD, renal biopsy is still a useful tool for managing immunosuppressive therapy, as well as for the knowledge of a specific renal diagnosis for transplant candidates [99]. Other studies confirmed that renal biopsy can lead to a change in therapeutic management in a significant percentage of patients with CKD of unknown origin $[9,100,101]$, although the risk-benefit profile of such procedures in the CKD population is not yet well defined.

\section{Diabetes Mellitus}

The utility of renal biopsy in patients with diabetes is another timely and debated issue [102, 103]. A common opinion is that patients with diabetes with proteinuria and other micro-vascular complications, such as retinopathy, are very likely to have a typical DN so that renal biopsy cannot give additional information for their clinical management [2]. However, a significant percentage of patients with diabetes may instead have a non-diabetic renal disease (NDRD), which can be even superimposed on a typical DN (mixed forms). Since clinical parameters such as proteinuria or albuminuria may not parallel with the great variability of renal histology [104], renal biopsy remains the gold standard for the correct assessment of renal damage in this setting and would be crucial for planning an optimal therapeutic approach (e.g. immunosuppressive therapies) [2].

So far, a discrete number of studies have investigated this issue [22, 104-150] (table 5). In these studies, indications for biopsy included the following: (1) a nephrotic range proteinuria or renal impairment in the absence of diabetic retinopathy; (2) a nephrotic range proteinuria or renal impairment with diabetes vintage less than 5 years or normal kidney function; (3) an unexplained microscopic hematuria or AKI; (4) a rapidly worsening of renal function in patients with a previously stable renal function. Diagnosis of DN ranged from 6.5\% [103] to $94 \%$ [140] of all the biopsies made. NDRD spanned from 3\% [134] to $82.9 \%$ [103], while mixed forms accounted for $4 \%$ [139] to $45.5 \%$ [107] of all the histological pictures. Moreover, Mazzucco et al. [129] identified a subgroup of patients with diabetes (15.2\%) characterized by the prevalence of severe vascular changes affecting glomeruli associated with marked arteriosclerosis and arteriolosclerosis in the absence of typical diabetic damage. IgAN was the most frequently observed NDRD $[22,103,107,112$, $114,117,126,128,134,140,141,144-146,148,150]$ with a prevalence ranging from $3 \%$ [134] to $59 \%$ [128]. MN was the predominant NDRD in 9 cohorts $[105,109,110$, $125,129,137-139]$ (7\% [139] to 35\% [109]); FSGS prevailed in $6 \%[106,116,122,131,132,136](17 \%[116]$ to $37.7 \%$ [131]), while AIN was the main NDRD in 4 studies $[111,127,143,147]$ (18\% [143] to $48.8 \%$ [111]).

\section{Renal Biopsy in the Elderly Setting}

Kidney disease is highly prevalent among elderly persons [151]. The aging kidney is characterized by structural and functional changes due to age and systemic disease (diabetes, hypertension, obesity) such as glomerulosclerosis, tubulo-interstitial fibrosis, atrophy and, consequently, a reduction in the functional renal reserve, which makes the elderly prone to develop CKD, sooner or later [152-154]. Although in most cases renal biopsy cannot differentiate between chronic renal damage and age-related changes, some specific conditions may require histological details for a clear-cut diagnosis, etiological frame-working and therapeutic planning [155]. Theoretically, the indications for performing renal biopsy in the elderly should not diverge from those in an adult, non-elderly population [69]; however, since old patients are more likely to present with decreased renal function, cardiovascular, pulmonary or hematologic comorbidities and poorer general health, a prudent and complete evaluation of risk factors is mandatory for guiding decision to biopsy [151]. Nevertheless, preliminary evidence suggests that the rate and type of complications in the elderly patients do not differ from those observed in the general population [156]. Kohli et al. [156] analyzed the rate of complications in 210 patients with native renal biopsies, of which 26 were done in elderly patients. The incidence of gross hematuria was higher in the elderly than in younger individuals ( 15 vs. $3 \%$ ), but the rate of more severe complications (hematuria with need of blood transfusions, perinephric hematoma, need of invasive interventions...) was not different between the 2 subgroups. In the study of Pincon et al. [157], only 5 old patients (3.3\%) presented biopsy-related complications. In another report [158], the incidence of post-biopsy complications in the elderly was similar to that seen in the nonelderly adults (11.9 vs. 10\%) and never required blood transfusion or invasive maneuvers.

As reported in table 6, data from 16 studies show that the 2 most common indications for RB in elderly populations are AKI (12\% [159] to 73\% [156]) and NS of rapid onset (13\% [160] to 68\% [159]). There is indeed great variability of histological pictures found in the elderly population, and even more in the very elderly $(\geq 80$ 
Table 6. Main studies on renal biopsy in elderly populations

\begin{tabular}{|c|c|c|c|c|}
\hline Okpechi et al. [165] & 111 & $>60$ & NS $(48.6 \%)$ & $\mathrm{MN}(14.4 \%), \mathrm{DN}(12.6 \%)$ \\
\hline Yokoyama et al. [162] & 276 & $>80$ & NS (50.7\%), AKI (22.5\%) & $\begin{array}{l}\text { MN (28\%), amyloidosis (11.9\%), MCD (11.9\%), } \\
\text { FSGS (7.5\%) }\end{array}$ \\
\hline Omokawa et al. [163] & 73 & $>80$ & NS, AKI, UA & $\mathrm{MN}, \mathrm{MCD}$ \\
\hline Brown et al. [152] & 236 & $>65$ & AKI (31.8\%), NS (25\%), proteinuria $(7.6 \%)$ & PICGN (17.4\%), AIN (11\%), MN (8.9\%) \\
\hline Pincon et al. [157] & 150 & $>70$ & AKI (31\%), NS (30\%), CKD (11\%) & $\begin{array}{l}\text { AIN (23\%), PICGN (22.5\%), vascula nephropathy } \\
(12 \%), \text { MPGN }(6.5 \%)\end{array}$ \\
\hline de Oliveira et al. [153] & 71 & $>60$ & NS (49.3\%), AKI (6.8\%), UA (16.9\%) & $\begin{array}{l}\text { MN }(50 \%) \text {, amyloidosis }(20 \%) \text {, FSGS }(20 \%) \\
\text { ATN }(35 \%) \text {, cast-nephropathy }(15 \%) \\
\text { post-infectious GN, DN, hypertensive damage }\end{array}$ \\
\hline Moutzouris et al. [160] & 235 & $>80$ & AKI (46.4\%), CKD (23.8\%), NS (13.2\%) & $\begin{array}{l}\text { PICGN (19\%), FSGS (7.6\%), } \\
\text { hypertensivenephrosclerosis (7.1\%), IgAN (7.1\%) }\end{array}$ \\
\hline Kohli et al. [156] & 26 & $>60$ & AKI (73\%), NS (27\%) & PICGN (15\%), AIN (15\%), cast nephropathy (11\%) \\
\hline Ferro et al. [166] & 150 & $>65$ & NS, AKI, CKD & PICGN \\
\hline Nair et al. [161] & 100 & $>80$ & $\begin{array}{l}\text { NS (33\%), AKI (23\%), nephriticsyndrome } \\
(20 \%)\end{array}$ & PICGN (19\%), FSGS (7\%), MCD (6\%) \\
\hline
\end{tabular}

ATN = Acute tubular necrosis; PICGN = pauci-immune crescentic glomerulonephritis; RB = renal biopsy; UA = urinary abnormalities .

years) $[160,161]$. In a recent analysis of Japanese renal biopsy registry [162], primary glomerular diseases, such as $\mathrm{MN}$, were the most common findings. In this registry amyloidosis, MN and ANCA-associated vasculitis prevailed in the elderly, while IgAN was more frequent in the non-elderly adults [163]. Amyloidosis was the most common diagnosis (16.9\%) among 71 very elderly patients (>85 years) in the Spanish registry of GN [164]. In a retrospective analysis of 111 elderly patients in South Africa, MN predominated (14.4\%) [165]. CrescGN is another common histologic finding among old persons $[92,152,156,160,161,166,167]$, with a frequency of overall diagnoses ranging from $15 \%$ [156] to $31 \%$ [92]. AIN is exceedingly prevalent in the elderly $[92,152,156$,
167]; in one retrospective study in Western France [157], AIN was even the most frequent histological report $(23 \%)$. Studies analyzing the clinical impact of renal biopsy on the management of the elderly patients show results that are in line with those reported in the general population. Histological diagnosis in the elderly patients may lead to targeted, successful treatment in $40 \%$ [161] to $67 \%$ of cases [160] or, at least, advise against potentially harmful approaches [160]. In the study of Pincon et al. [157], 64\% of the elderly nephrotic patients receiving immunosuppressive therapy after renal diagnosis made by biopsy were more likely to have complete or partial remission of their disease as well as an improvement in survival.
14 


\section{Conclusions}

Although renal biopsy can be considered a determinant factor for characterizing renal diseases and for collecting useful diagnostic and prognostic information, the clinical application of this technique and the correspondent histological findings are highly variable across the world. This is mostly a consequence of lack of consensus in national and single-center biopsy policies which, in turn, depends on the disagreement on the real indications for this procedure. The utility of renal biopsy is related to the possibility to assess the extent of renal damage for appropriate and timely intervention to delay the progression of ESKD in patients with NS, urinary abnormalities, acute or chronic kidney failure and in renal injuries related to systemic diseases such as SLE, diabetes, vasculitides or myeloma. Our evidence-based approach to the current literature indicates that renal biopsy should be mandatory to assess the type and degree of lesions and to guide the therapeutic management in adults with NS. Renal biopsy might be highly informative in patients with coexistence of unexplained hematuria and proteinuria or in children with severe proteinuria non-respondent to corticosteroid treatment. Furthermore, this procedure may give important diagnostic and prognostic information in non-pre-renal and non-obstructive AKI, as the histology awareness may lead to substantial change in therapeutic management. However, in AKI patients, potential benefits of renal biopsy should always be weighted to the risk of bleeding complications. In patients presenting with IMH, low proteinuria or early unexplained CKD, the choice of performing renal biopsy should be evaluated on a caseby-case basis, taking into account the possibility of improving the disease management. Indications for renal biopsy in the elderly should not differ from those in the general population, as there is no convincing evidence that an older age conveys a higher risk of complications. Conversely, renal biopsy appears to be of limited utility in patients with unexplained advanced CKD where risks outweigh possible improvements in clinical management. Finally, in patients with diabetes with short duration of disease ( $<5$ years), severe proteinuria, rapid onset or worsening of renal impairment, particularly in the absence of diabetic retinopathy, renal biopsy should be advocated for excluding the presence of a NDRD. Considering the relative safety and the low risk of complications of this procedure, future improvement in renal biopsy practice due to widespread access to educational programs and renal biopsy courses may contribute to an increase in awareness of the need of renal biopsy in patient care.

\section{Acknowledgments}

We are grateful of the European Renal Best Practice and ERAEDTA Immunonephrology Working Group for the incessant support to the project. This study was financed by a grant of the Italian Society of Nephrology.

\section{Disclosure Statement}

All authors declare no conflicts of interest.

\section{References}

1 USRDS - United States renal data system 2013 annual report (accessed July 15, 2014).

2 Gonzalez Suarez ML, Thomas DB, Barisoni L, Fornoni A: Diabetic nephropathy: is it time yet for routine kidney biopsy? World J Diabetes 2013;4:245-255.

3 Gilbertson DT, Collins AJ: Projecting the ESRD population to 2020. 2007. http://www. usrds.org/2007/pres/GILBERTSON_ASN_ PRESENTATION_11_2_07_tmp.swf (accessed July 21,2014 ).

4 ERA-EDTA registry annual report 2012. http://www.era-edta-reg.org/index.jsp?p=14 (accessed July 15, 2014).

5 Mullen W, Delles C, Mischak H; EuroKUP COST action: Urinary proteomics in the assessment of chronic kidney disease. Curr Opin Nephrol Hypertens 2011;20:654661.

Epidemiology and Indications for Renal Biopsy
6 Hogan JJ, Mocanu M, Berns JS: The native kidney biopsy: update and evidence for best practice. Clin J Am Soc Nephrol 2015; pii: CJN.05750515.

7 Dhaun N, Bellamy CO, Cattran DC, Kluth DC: Utility of renal biopsy in the clinical management of renal disease. Kidney Int 2014;85: 1039-1048.

8 Alexopoulos E: How important is renal biopsy in the management of patients with glomerular diseases? Nephrol Dial Transplant 2001;16(suppl 6):83-85.

9 Richards NT, Darby S, Howie AJ, Adu D, Michael J: Knowledge of renal histology alters patient management in over $40 \%$ of cases. Nephrol Dial Transplant 1994;9:1255-1259.

10 Reddy J, Lynn KL, Bailey RR: Renal biopsy: an appraisal of its role in clinical nephrology. $\mathrm{N}$ Z Med J 1981;94:96-98.
11 Favre H: [Indications for renal biopsy]. Schweiz Med Wochenschr 1989;119:868-871.

12 Holman B, Jezikova A, Funiakova M, Galajda P, Makovicky P, Mokan M: [Glomerulonephritides, histology forms, way of treatment and therapeutic effect in our patients]. Vnitr Lek 2004;50:434-437.

13 Turner MW, Hutchinson TA, Barre PE, Prichard S, Jothy S: A prospective study on the impact of the renal biopsy in clinical management. Clin Nephrol 1986;26:217-221.

14 Shah RP, Vathsala A, Chiang GS, Chin YM, Woo KT: The impact of percutaneous renal biopsies on clinical management. Ann Acad Med Singapore 1993;22:908-911.

15 Pfister M, Jakob S, Frey FJ, Niederer U, Schmidt M, Marti HP: Judgment analysis in clinical nephrology. Am J Kidney Dis 1999; 34:569-575. 
16 Gilg J, Rao A, Fogarty D: UK renal registry 16th annual report: chapter 1 UK renal replacement therapy incidence in 2012: national and centre-specific analyses. Nephron Clin Pract 2013;125:1-27.

17 Sugiyama H, Yokoyama H, Sato H, et al: Japan renal biopsy registry and Japan kidney disease registry: committee report for 2009 and 2010. Clin Exp Nephrol 2013;17:155-173.

18 Polito MG, de Moura LA, Kirsztajn GM: An overview on frequency of renal biopsy diagnosis in Brazil: clinical and pathological patterns based on 9,617 native kidney biopsies. Nephrol Dial Transplant 2010;25:490496.

19 McQuarrie EP, Mackinnon B, Young B, et al: Centre variation in incidence, indication and diagnosis of adult native renal biopsy in Scotland. Nephrol Dial Transplant 2009;24: 1524-1528.

20 Al Arrayed A, Shariff S, Al Maamari MM: Kidney disease in Bahrain: a biopsy based epidemiologic study. Saudi J Kidney Dis Transpl 2007; 18:638-642.

21 Mazzuchi N, Acosta N, Caorsi H, et al: [Frequency of diagnosis and clinic presentation of glomerulopathies in Uruguay]. Nefrologia 2005; $25: 113-120$

22 Rychlik I, Jancova E, Tesar V, et al: The Czech registry of renal biopsies. Occurrence of renal diseases in the years 1994-2000. Nephrol Dial Transplant 2004;19:3040-3049.

23 Rivera F, Lopez-Gomez JM, Perez-Garcia R; Spanish Registry of Glomerulonephritis: Clinicopathologic correlations of renal pathology in Spain. Kidney Int 2004;66:898-904.

24 Gesualdo L, Di Palma AM, Morrone LF, Strippoli GF, Schena FP; Italian Immunopathology Group, Italian Society of Nephrology: The Italian experience of the national registry of renal biopsies. Kidney Int 2004;66:890-894.

25 Rivera F, Lopez-Gomez JM, Perez-Garcia R; Spanish Registry of Glomerulonephritis: Frequency of renal pathology in Spain 1994-1999. Nephrol Dial Transplant 2002;17:1594-1602.

26 Heaf J, Løkkegaard H, Larsen S: The epidemiology and prognosis of glomerulonephritis in Denmark 1985-1997. Nephrol Dial Transplant 1999;14:1889-1897.

27 Schena FP: Survey of the Italian registry of renal biopsies. Frequency of the renal diseases for 7 consecutive years. The Italian Group of Renal Immunopathology. Nephrol Dia Transplant 1997;12:418-426.

28 Maixnerova D, Jancova E, Skibova J, et al: $\mathrm{Na}-$ tionwide biopsy survey of renal diseases in the Czech Republic during the years 1994-2011. J Nephrol 2015;28:39-49.

29 Braun N, Schweisfurth A, Lohöfener C, Lange C, Gründemann C, Kundt G, Gröne HJ: Epidemiology of glomerulonephritis in Northern Germany. Int Urol Nephrol 2011;43:11171126.

30 Simon P, Ramee MP, Boulahrouz R, et al: Epidemiologic data of primary glomerular diseases in western France. Kidney Int 2004;66: 905-908.
31 Simon P, Ramee MP, Autuly V, et al: Epidemiology of primary glomerular diseases in a French region. Variations according to period and age. Kidney Int 1994;46:1192-1198.

32 Briganti EM, Dowling J, Finlay M, et al: The incidence of biopsy-proven glomerulonephritis in Australia. Nephrol Dial Transplant 2001;16:1364-1367.

33 Covic A, Schiller A, Volovat C, et al: Epidemiology of renal disease in Romania: a 10 year review of two regional renal biopsy databases. Nephrol Dial Transplant 2006;21:419-424.

34 Wirta O, Mustonen J, Helin H, Pasternack A: Incidence of biopsy-proven glomerulonephritis. Nephrol Dial Transplant 2008;23: 193-200.

35 Jalalah SM: Patterns of primary glomerular diseases among adults in the western region of Saudi Arabia. Saudi J Kidney Dis Transpl 2009;20:295-299.

36 Riispere Z, Ots-Rosenberg M: Occurrence of kidney diseases and patterns of glomerular disease based on a 10-year kidney biopsy material: a retrospective single-centre analysis in Estonia. Scand J Urol Nephrol 2012;46:389394.

37 Okpechi I, Swanepoel C, Duffield M, et al: Patterns of renal disease in Cape Town South Africa: a 10-year review of a single-centre renal biopsy database. Nephrol Dial Transplant 2011;26:1853-1861.

38 Naumovic R, Pavlovic S, Stojkovic D, BastaJovanovic G, Nesic V: Renal biopsy registry from a single centre in Serbia: 20 years of experience. Nephrol Dial Transplant 2009;24: 877-885.

39 Hanko JB, Mullan RN, O'Rourke DM, McNamee PT, Maxwell AP, Courtney AE: The changing pattern of adult primary glomerular disease. Nephrol Dial Transplant 2009;24:3050-3054.

40 Chang JH, Kim DK, Kim HW, et al: Changing prevalence of glomerular diseases in Korean adults: a review of 20 years of experience. Nephrol Dial Transplant 2009;24:2406-2410.

41 Naini AE, Harandi AA, Ossareh S, Ghods A, Bastani B: Prevalence and clinical findings of biopsy-proven glomerulonephritidis in Iran. Saudi J Kidney Dis Transpl 2007;18:556-564.

42 Swaminathan S, Leung N, Lager DJ, et al: Changing incidence of glomerular disease in Olmsted County, Minnesota: a 30-year renal biopsy study. Clin J Am Soc Nephrol 2006;1: 483-487.

43 Narasimhan B, Chacko B, John GT, Korula A, Kirubakaran MG, Jacob CK: Characterization of kidney lesions in Indian adults: towards a renal biopsy registry. J Nephrol 2006;19:205210.

44 van Paassen P, van Breda Vriesman PJ, van Rie H, Tervaert JW: Signs and symptoms of thin basement membrane nephropathy: a prospective regional study on primary glomerular disease - the Limburg renal registry. Kidney Int 2004;66:909-913.

45 Li LS, Liu ZH: Epidemiologic data of renal diseases from a single unit in China: analysis based on 13,519 renal biopsies. Kidney Int 2004;66:920-923.

46 Polenakovic MH, Grcevska L, Dzikova S: The incidence of biopsy-proven primary glomerulonephritis in the Republic of Macedonia long-term follow-up. Nephrol Dial Transplant 2003;18(suppl 5):v26-v27.

47 Chan KW, Chan TM, Cheng IK: Clinical and pathological characteristics of patients with glomerular diseases at a university teaching hospital: 5-year prospective review. Hong Kong Med J 1999;5:240-244.

48 Braun N, Schweisfurth A, Lohofener C, et al: Epidemiology of glomerulonephritis in Northern Germany. Int Urol Nephrol 2011; 43:1117-1126.

49 Hurtado A, Johnson RJ: Hygiene hypothesis and prevalence of glomerulonephritis. Kidney Int Suppl 2005;97:S62-S67.

50 Cagnoli L; Italian Society of Nephrology: [Instructions and implementations for percutaneous renal biopsy. Guidelines for the therapy of glomerular nephropathies]. G Ital Nefrol 2003;20(suppl 24):S3-S47.

51 Mota PC: [Indications for renal biopsy]. Acta Med Port 2005; 18:147-151.

52 Quiros PL, Ceballos M, Remon C, et al: [Study of the biopsied nephrotic syndrome for 20 years in the Cadiz Bay Area: histological correspondence, renal prognosis and clinical prognostic factors]. Nefrologia 2005;25:147154.

53 Horvatic I, Tisljar M, Bulimbasic S, Bozic B, Galesic Ljubanovic D, Galesic K: Epidemiologic data of adult native biopsy-proven renal diseases in Croatia. Int Urol Nephrol 2013;45: 1577-1587.

54 Kodner C: Nephrotic syndrome in adults: diagnosis and management. Am Fam Physician 2009;80:1129-1134.

55 Adu D: The nephrotic syndrome: does renal biopsy affect management? Nephrol Dial Transplant 1996;11:12-14.

56 Bajaj S, Albert L, Gladman DD, Urowitz MB Hallett DC, Ritchie S: Serial renal biopsy in systemic lupus erythematosus. J Rheumatol 2000;27:2822-2826.

57 Wang GB, Xu ZJ, Liu HF, Zhou QG, Zhou $\mathrm{ZM}$, Jia N: Changes in pathological pattern and treatment regimens based on repeat renal biopsy in lupus nephritis. Chin Med J (Engl) 2012;125:2890-2894.

58 Hii IM, Chen ML, Chang CC: Benign monoclonal gammopathy-associated acute kidney injury: case report and literature review. Ren Fail 2010;32:636-638.

59 Kassirer JP: Is renal biopsy necessary for optimal management of the idiopathic nephrotic syndrome? Kidney Int 1983;24:561-575.

60 Richards NT, Darby S, Howie AJ, Adu D, Michael J: Knowledge of renal histology alters patient management in over $40 \%$ of cases. Nephrol Dial Transplant 1994;9:1255-1259.

61 Cohen AH, Nast CC, Adler SG, Kopple JD: Clinical utility of kidney biopsies in the diagnosis and management of renal disease. Am J Nephrol 1989;9:309-315. 
62 Nephrotic syndrome in children: prediction of histopathology from clinical and laboratory characteristics at time of diagnosis. A report of the international study of kidney disease in children. Kidney Int 1978;13:159-165.

63 Mubarak M, Lanewala A, Kazi JI, et al: Histopathological spectrum of childhood nephrotic syndrome in Pakistan. Clin Exp Nephrol 2009;13:589-593.

64 Gooden M, Miller M, Shah D, Soyibo AK, Williams J, Barton EN: Clinicopathological features of atypical nephrotic syndrome in Jamaican children. West Indian Med J 2010;59: 319-324.

65 Mattoo TK: Kidney biopsy prior to cyclophosphamide therapy in primary nephrotic syndrome. Pediatr Nephrol 1991;5:617-619.

66 Stadermann MB, Lilien MR, van de Kar NC, Monnens LA, Schroder CH: Is biopsy required prior to cyclophosphamide in steroidsensitive nephrotic syndrome? Clin Nephrol 2003;60:315-317.

67 Primack WA, Schulman SL, Kaplan BS: An analysis of the approach to management of childhood nephrotic syndrome by pediatric nephrologists. Am J Kidney Dis 1994;23:524527.

68 Hama T, Nakanishi K, Shima Y, et al: Renal biopsy criterion in children with asymptomatic constant isolated proteinuria. Nephrol Dial Transplant 2012;27:3186-3190.

69 Fuiano G, Mazza G, Comi N, et al: Current indications for renal biopsy: a questionnairebased survey. Am J Kidney Dis 2000;35:448457.

70 Trachtman H, Bergwerk A, Gauthier B: Isolated proteinuria in children. Natural history and indications for renal biopsy. Clin Pediatr (Phila) 1994;33:468-472.

71 Rollino C, Beltrame G, Ferro M, Quattrocchio G, Quarello F: [Isolated microhematuria: biopsy, yes or no?]. G Ital Nefrol 2010;27:367-373.

72 Trachtman H, Weiss RA, Bennett B, Greifer I: Isolated hematuria in children: indications for a renal biopsy. Kidney Int 1984;25:94-99.

73 Zhai Y, Xu H, Shen Q, et al: Renal histological features of school-age children with asymptomatic haematuria and/or proteinuria: a multicenter study. Nephrology (Carlton) 2014; 19:426-431.

74 Hisano S, Kwano M, Hatae K, et al: Asymptomatic isolated microhaematuria: natural history of 136 children. Pediatr Nephrol 1991; 5:578-581.

75 Lee YM, Baek SY, Kim JH, Kim DS, Lee JS, Kim PK: Analysis of renal biopsies performed in children with abnormal findings in urinary mass screening. Acta Paediatr 2006;95:849853.

76 Moreno JA, Martin-Cleary C, Gutierrez E, et al: Haematuria: the forgotten CKD factor? Nephrol Dial Transplant 2012;27:28-34.

77 Yu MC, Lee F, Huang WH, Hsueh S: Percutaneous ultrasound-guided renal biopsy in children: the need for renal biopsy in pediatric patients with persistent asymptomatic microscopic hematuria. Biomed J 2014;37:391-397.
78 Eardley KS, Ferreira MA, Howie AJ, Gosling P, Lipkin GW: Urinary albumin excretion: a predictor of glomerular findings in adults with microscopic haematuria. QJM 2004;97: 297-301.

79 Feng CY, Xia YH, Wang WJ, et al: Persistent asymptomatic isolated hematuria in children: clinical and histopathological features and prognosis. World J Pediatr 2013;9:163-168.

80 Truniger B: [Microhematuria of renal origin differential diagnosis, clarification and interpretation]. Schweiz Med Wochenschr 1987; 117:1993-1998

81 Fogazzi GB, Garigali G, Pirovano B, Muratore MT, Raimondi S, Berti S: How to improve the teaching of urine microscopy. Clin Chem Lab Med 2007;45:407-412.

82 McGregor DO, Lynn KL, Bailey RR, Robson RA, Gardner J: Clinical audit of the use of renal biopsy in the management of isolated microscopic hematuria. Clin Nephrol 1998;49: 345-348.

83 McGregor DO, Lynn KL, Bailey RR, Robson RA, Gardner J: Clinical audit of the use of renal biopsy in the management of isolated $\mathrm{mi}$ croscopic hematuria. Clin Nephrol 1998;49: 345-348.

84 Shen P, He L, Jiang Y, Wang C, Chen M: Useful indicators for performing renal biopsy in adult patients with isolated microscopic haematuria. Int J Clin Pract 2007;61:789-794.

85 Dimitrijevic J, Kovacevic Z, Jovanovic D, Ignjatovic L, Rabrenovic V, Djukanovic L: Asymptomatic urinary abnormalities: histopathological analysis. Pathol Res Pract 2009; 205:295-302.

86 Kiyoshi Y, Hisano S, Takebayashi S: [Importance of the duration from the onset of a urinary abnormality until a biopsy is performed: a multivariate analysis on the application of renal biopsy for patients with IgA nephropathy]. Nihon Jinzo Gakkai Shi 1998;40:547-554.

87 Chow KM, Kwan BC, Li PK, Szeto CC: Asymptomatic isolated microscopic haematuria: long-term follow-up. QJM 2004;97:739_ 745.

88 Torres Munoz A, Valdez-Ortiz R, GonzalezParra C, Espinoza-Davila E, Morales-Buenrostro LE, Correa-Rotter R: Percutaneous renal biopsy of native kidneys: efficiency, safety and risk factors associated with major complications. Arch Med Sci Oct 2011;7:823-831.

89 Corapi KM, Chen JL, Balk EM, Gordon CE Bleeding complications of native kidney biopsy: a systematic review and meta-analysis. Am J Kidney Dis 2012;60:62-73.

90 Wilson DM, Turner DR, Cameron JS, Ogg CS, Brown CB, Chantler C: Value of renal biopsy in acute intrinsic renal failure. $\mathrm{Br}$ Med J 1976;2:459-461.

91 Beaman M, Turney JH, Rodger RS, McGonigle RS, Adu D, Michael J: Changing pattern of acute renal failure. Q J Med 1987;62:15-23.

92 Haas M, Spargo BH, Wit EJ, Meehan SM: Etiologies and outcome of acute renal insufficiency in older adults: a renal biopsy study of 259 cases. Am J Kidney Dis 2000;35:433-447.
93 Farrington K, Levison DA, Greenwood RN Cattell WR, Baker LR: Renal biopsy in patients with unexplained renal impairment and normal kidney size. Q J Med 1989;70: 221-233.

94 Joseph AJ, Compton SP, Holmes LH, et al: Utility of percutaneous renal biopsy in chronic kidney disease. Nephrology (Carlton) 2010;15:544-548.

95 Curtis JJ, Rakowski TA, Argy WP Jr, Schreiner GE: Evaluation of percutaneous kidney biopsy in advanced renal failure. Nephron 1976;17:259-269.

96 Kropp KA, Shapiro RS, Jhunjhunwala JS: Role of renal biopsy in end stage renal failure. Urology 1978;12:631-634.

97 Sobh M, Moustafa F, Ghoniem M: Value of renal biopsy in chronic renal failure. Int Urol Nephrol 1988;20:77-83.

98 Lupo A, Bernich P, Antonucci F, Dugo M, Riegler P, Carraro M: [Kidney diseases with chronic renal failure in the Italian renal biopsy registries]. G Ital Nefrol 2008; 25(suppl 44):S20-S26.

99 Zaza G, Bernich P, Lupo A; 'Triveneto' Register of Renal Biopsies (TVRRB): Renal biopsy in chronic kidney disease: lessons from a large Italian registry. Am J Nephrol 2013; 37:255-263.

100 Cohen AH, Nast CC, Adler SG, Kopple JD: Clinical utility of kidney biopsies in the diagnosis and management of renal disease. Am J Nephrol 1989;9:309-315

101 Paone DB, Meyer LE: The effect of biopsy on therapy in renal disease. Arch Intern Med 1981;141:1039-1041.

102 Sharma SG, Bomback AS, Radhakrishnan J, et al: The modern spectrum of renal biopsy findings in patients with diabetes. Clin J Am Soc Nephrol 2013;8:1718-1724.

103 Zhuo L, Ren W, Li W, Zou G, Lu J: Evaluation of renal biopsies in type 2 diabetic patients with kidney disease: a clinicopathological study of 216 cases. Int Urol Nephrol 2013;45:173-179.

104 Fioretto P, Mauer M, Brocco E, et al: Patterns of renal injury in NIDDM patients with microalbuminuria. Diabetologia 1996; 39:1569-1576.

105 Akimoto T, Ito C, Saito O, et al: Microscopic hematuria and diabetic glomerulosclerosis - clinicopathological analysis of type 2 diabetic patients associated with overt proteinuria. Nephron. Clin Prac 2008;109:c119c126.

106 Arif M, Arif MK, Arif MS: An evaluation of renal biopsy in type-II diabetic patients. J Coll Physicians Surg Pak 2009;19:627-631.

107 Bi H, Chen N, Ling G, Yuan S, Huang G, Liu $\mathrm{R}$ : Nondiabetic renal disease in type 2 diabetic patients: a review of our experience in 220 cases. Ren Fail 2011;33:26-30.

108 Biesenbach G, Bodlaj G, Pieringer H, Sedlak M: Clinical versus histological diagnosis of diabetic nephropathy - is renal biopsy required in type 2 diabetic patients with renal disease? QJM 2011;104:771-774. 
109 Castellano I, Covarsi A, Novillo R, GomezMartino JR, Ferrando L: [Renal histological lesions in patients with type II diabetes mellitus]. Nefrologia 2002;22:162-169.

110 Chang TI, Park JT, Kim JK, et al: Renal outcomes in patients with type 2 diabetes with or without coexisting non-diabetic renal disease. Diabetes Res Clin Pract 2011;92:198204.

111 Chong YB, Keng TC, Tan LP, et al: Clinical predictors of non-diabetic renal disease and role of renal biopsy in diabetic patients with renal involvement: a single centre review. Ren Fail 2012;34:323-328.

112 Christensen PK, Larsen S, Horn T, Olsen S, Parving HH: Causes of albuminuria in patients with type 2 diabetes without diabetic retinopathy. Kidney Int 2000;58:17191731.

113 Cordonnier DJ, Pinel N, Barro C, et al: Expansion of cortical interstitium is limited by converting enzyme inhibition in type 2 diabetic patients with glomerulosclerosis. The Diabiopsies Group. J Am Soc Nephrol 1999; 10:1253-1263.

114 Gambara V, Mecca G, Remuzzi G, Bertani T: Heterogeneous nature of renal lesions in type II diabetes. J Am Soc Nephrol 1993;3: 1458-1466.

115 Ghani AA, Al Waheeb S, Al Sahow A, Hussain N: Renal biopsy in patients with type 2 diabetes mellitus: indications and nature of the lesions. Ann Saudi Med 2009;29:450453.

116 Haider DG, Peric S, Friedl A, et al: Kidney biopsy in patients with diabetes mellitus. Clin Nephrol 2011;76:180-185.

117 Harada K, Akai Y, Sumida K, et al: Significance of renal biopsy in patients with presumed diabetic nephropathy. J Diabetes Investig 2013;4:88-93.

118 Hashim Al-Saedi AJ: Pathology of nondiabetic glomerular disease among adult Iraqi patients from a single center. Saudi J Kidney Dis Transpl 2009;20:858-861.

119 Hironaka K, Makino H, Ikeda S, Haramoto T, Ota Z: Nondiabetic renal disease complicating diabetic nephropathy. J Diabet Complications 1991;5:148-149.

120 Huang F, Yang Q, Chen L, Tang S, Liu W, $\mathrm{Yu}$ X: Renal pathological change in patients with type 2 diabetes is not always diabetic nephropathy: a report of 52 cases. Clin Nephrol 2007;67:293-297.

121 Insalaco M, Zamboli P, Floccari F, et al: Indication to renal biopsy in DM2 patients: potential role of intrarenal resistive index. Arch Ital Urol Androl 2012;84:283-286.

122 Izzedine H, Fongoro S, Pajot O, Beaufils $\mathrm{H}$, Deray G: Retinopathy, hematuria, and diabetic nephropathy. Nephron 2001;88:382383.

123 John GT, Date A, Korula A, Jeyaseelan L, Shastry JC, Jacob CK: Nondiabetic renal disease in noninsulin-dependent diabetics in a south Indian Hospital. Nephron 1994;67: 441-443.
124 Kharrat M, Kammoun K, Charfeddine K, et al: [Renal biopsy findings in diabetes mellitus]. Tunis Med 2007;85:216-219.

125 Kleinknecht D, Bennis D, Altman JJ: Increased prevalence of non-diabetic renal pathology in type II diabetes mellitus. Nephrol Dial Transplant 1992;7:1258-1259.

126 Lee EY, Chung CH, Choi SO: Non-diabetic renal disease in patients with non-insulin dependent diabetes mellitus. Yonsei Med J 1999;40:321-326.

127 Lin YL, Peng SJ, Ferng SH, Tzen CY, Yang CS: Clinical indicators which necessitate renal biopsy in type 2 diabetes mellitus patients with renal disease. Int J Clin Pract 2009;63:1167-1176.

128 Mak SK, Gwi E, Chan KW, et al: Clinical predictors of non-diabetic renal disease in patients with non-insulin dependent diabetes mellitus. Nephrol Dial Transplant 1997;12: 2588-2591.

129 Mazzucco G, Bertani T, Fortunato M, et al: Different patterns of renal damage in type 2 diabetes mellitus: a multicentric study on 393 biopsies. Am J Kidney Dis 2002;39:713720.

130 Moger V, Kumar SK, Sakhuja V, et al: Rapidly progressive renal failure in type 2 diabetes in the tropical environment: a clinico-pathological study. Ren Fail 2005;27:595-600.

131 Mou S, Wang Q, Liu J, et al: Prevalence of non-diabetic renal disease in patients with type 2 diabetes. Diabetes Res Clin Pract 2010;87:354-359.

132 Nzerue CM, Hewan-Lowe K, Harvey P, Mohammed D, Furlong B, Oster R: Prevalence of non-diabetic renal disease among African-American patients with type II diabetes mellitus. Scand J Urol Nephrol 2000; 34:331-335.

133 Oh SW, Kim S, Na KY, et al: Clinical implications of pathologic diagnosis and classification for diabetic nephropathy. Diabetes Res Clin Pract 2012;97:418-424.

134 Olsen S, Mogensen CE: How often is NIDDM complicated with non-diabetic renal disease? An analysis of renal biopsies and the literature. Diabetologia 1996;39:1638-1645.

135 Parving HH, Gall MA, Skott P, et al: Prevalence and causes of albuminuria in non-insulin-dependent diabetic patients. Kidney Int 1992;41:758-762.

136 Pham TT, Sim JJ, Kujubu DA, Liu IL, Kumar VA: Prevalence of nondiabetic renal disease in diabetic patients. Am J Nephrol 2007;27: 322-328.

137 Prakash J, Lodha M, Singh SK, Vohra R, Raja $R$, Usha: Diabetic retinopathy is a poor predictor of type of nephropathy in proteinuric type 2 diabetic patients. J Assoc Physicians India 2007;55:412-416.

138 Premalatha G, Vidhya K, Deepa R, Ravikumar R, Rema M, Mohan V: Prevalence of non-diabetic renal disease in type 2 diabetic patients in a diabetes centre in Southern India. J Assoc Physicians India 2002;50: 1135-1139.
139 Richards NT, Greaves I, Lee SJ, Howie AJ, Adu D, Michael J: Increased prevalence of renal biopsy findings other than diabetic glomerulopathy in type II diabetes mellitus. Nephrol Dial Transplant 1992; 7:397399.

140 Schwartz MM, Lewis EJ, Leonard-Martin T, Lewis JB, Batlle D: Renal pathology patterns in type II diabetes mellitus: relationship with retinopathy. The Collaborative Study Group. Nephrol Dial Transplant 1998;13: 2547-2552.

141 Serra A, Romero R, Bayes B, Lopez D, Bonet J: Is there a need for changes in renal biopsy criteria in proteinuria in type 2 diabetes? Diabetes Res Clin Pract 2002;58: 149-153.

142 Shen FC, Lee CT, Sun CK, et al: Prevalence of haematuria positively associated with urine albumin excretion in Type 2 diabetes. Diabet Med 2012;29:1178-1183.

143 Soni SS, Gowrishankar S, Kishan AG, Raman A: Non diabetic renal disease in type 2 diabetes mellitus. Nephrology (Carlton) 2006;11:533-537.

144 Suzuki D, Takano H, Toyoda M, et al: Evaluation of renal biopsy samples of patients with diabetic nephropathy. Intern Med 2001;40:1077-1084.

145 Tone A, Shikata K, Matsuda M, et al: Clinical features of non-diabetic renal diseases in patients with type 2 diabetes. Diabetes Res Clin Pract 2005;69:237-242.

146 Wong TY, Choi PC, Szeto CC, et al: Renal outcome in type 2 diabetic patients with or without coexisting nondiabetic nephropathies. Diabetes Care 2002;25:900-905.

147 Yaqub S, Kashif W, Hussain SA: Non-diabetic renal disease in patients with type-2 diabetes mellitus. Saudi J Kidney Dis Transpl 2012;23:1000-1007.

148 Y Z, Benyahia M, Ibrahim DM, et al: [Nondiabetic renal disease in type II diabetes mellitus patients in Mohammed V Military Hospital, Rabat, Morocco]. East Mediterr Health J 2012;18:620-623.

149 Zhang PP, Ge YC, Li SJ, Xie HL, Li LS, Liu $\mathrm{ZH}$ : Renal biopsy in type 2 diabetes: timing of complications and evaluating of safety in Chinese patients. Nephrology (Carlton) 2011;16:100-105.

150 Zhou J, Chen X, Xie Y, Li J, Yamanaka N, Tong X: A differential diagnostic model of diabetic nephropathy and non-diabetic renal diseases. Nephrol Dial Transplant 2008; 23:1940-1945.

151 Mohamed N, John R: Use of renal biopsy in the elderly. Int Urol Nephrol 2011;43:593600 .

152 Brown CM, Scheven L, O'Kelly P, Dorman AM, Walshe JJ: Renal histology in the elderly: indications and outcomes. J Nephrol 2012;25:240-244.

153 de Oliveira CM, Costa RS, Vieira Neto OM, et al: Renal diseases in the elderly underwent to percutaneous biopsy of native kidneys. J Bras Nefrol 2010;32:379-385. 
154 Bolignano D, Mattace-Raso F, Sijbrands EJ, Zoccali C: The aging kidney revisited: a systematic review. Ageing Res Rev 2014;14:6580.

155 Dhaun N, Bellamy CO, Cattran DC, Kluth DC: Utility of renal biopsy in the clinical management of renal disease. Kidney Int 2014;85:1039-1048.

156 Kohli HS, Jairam A, Bhat A, et al: Safety of kidney biopsy in elderly: a prospective study. Int Urol Nephrol 2006;38:815-820.

157 Pincon E, Rioux-Leclercq N, Frouget T, Le Pogamp P, Vigneau C: Renal biopsies after 70 years of age: a retrospective longitudinal study from 2000 to 2007 on 150 patients in Western France. Arch Gerontol Geriatr 2010;51:e120-e124.

158 Di Palma AM, d'Apollo AM, Vendemia F, Stallone G, Infante B, Gesualdo L: Kidney biopsy in the elderly. J Nephrol 2010;23(suppl 15):S55-S60.
159 Moulin B, Dhib M, Sommervogel C, Dubois D, Godin M, Fillastre JP: [Value of renal biopsy in the elderly. 32 cases]. Presse Med 1991;20:1881-1885.

160 Moutzouris DA, Herlitz L, Appel GB, et al: Renal biopsy in the very elderly. Clin J Am Soc Nephrol 2009;4:1073-1082.

161 Nair R, Bell JM, Walker PD: Renal biopsy in patients aged 80 years and older. Am J Kidney Dis 2004;44:618-626.

162 Yokoyama H, Sugiyama H, Sato H, et al: Renal disease in the elderly and the very elderly Japanese: analysis of the Japan Renal Biopsy Registry (J-RBR). Clin Exp Nephrol 2012;16: 903-920.

163 Omokawa A, Komatsuda A, Nara M, et al: Renal biopsy in patients aged 80 years and older: a single-center experience in Japan. Clin Nephrol 2012;77:461-467.
164 Verde E, Quiroga B, Rivera F, Lopez-Gomez JM: Renal biopsy in very elderly patients: data from the Spanish registry of glomerulonephritis. Am J Nephrol 2012;35:230237.

165 Okpechi IG, Ayodele OE, Rayner BL, Swanepoel CR: Kidney disease in elderly South Africans. Clin Nephrol 2013;79:269-276.

166 Ferro G, Dattolo P, Nigrelli S, Michelassi S, Pizzarelli F: Clinical pathological correlates of renal biopsy in elderly patients. Clin Nephrol 2006;65:243-247.

167 Heras M, Saiz A, Sanchez R, et al: [Renal biopsy in patients aged 65 years or older: are there differences in the indication and histopathology compared to other patients?]. Rev Esp Geriatr Gerontol 2010;45:316-319.

168 Mbakop A, Chatelanat F: [Renal puncture biopsy in the aged subject: apropos of 119 cases]. Ann Pathol 1985;5:101-105. 